\title{
Ship collision risk assessment for the Singapore Strait
}

\author{
Xiaobo Qu ${ }^{a}$, Qiang Meng ${ }^{a 1}$, Li Suyi $^{b}$ \\ ${ }^{a}$ Department of Civil and Environmental Engineering, National University of Singapore, \\ Singapore 117576 \\ ${ }^{b}$ Centre for Maritime Studies, National University of Singapore, Singapore 118411
}

\begin{abstract}
ABASTRACT
The Singapore Strait is considered as the bottleneck and chokepoint of the shipping routes connecting the Indian and the Pacific Ocean. Therefore, the ship collision risk assessment is of significant importance for ships passing through the narrow, shallow, and busy waterway. In this paper, three ship collision risk indices are initially proposed to quantitatively assess the ship collision risks in the Strait: index of speed dispersion, degree of acceleration and deceleration, and number of fuzzy ship domain overlaps. These three risk indices for the Singapore Strait are estimated by using the real-time ship locations and sailing speeds provide by Lloyd's MIU automatic identification system (AIS). Based on estimation of these three risk indices, it can be concluded that Legs $4 \mathrm{~W}, 5 \mathrm{~W}, 11 \mathrm{E}$, and $12 \mathrm{E}$ are the most risky legs in the Strait. Therefore, the ship collision risk reduction solutions should be prioritized being implemented in these four legs. This study also finds that around $25 \%$ of the vessels sail with a speed in excess of the speed limit, which results in higher potentials of ship collision. Analysis indicates that the safety level would be significantly improved if all the vessels follow the passage guidelines.
\end{abstract}

Keywords: Risk assessment, ship collision, the Singapore Strait, ship domain

\footnotetext{
${ }^{1}$ Corresponding author, Tel.: +65-65165494; fax +65 67791635

E-mail: cvemq@nus.edu.sg (Meng Qiang)
} 


\section{Introduction}

The Strait of Malacca and Singapore is one of the most important shipping channels in the world. It is the shortest shipping route from the Indian Ocean to the Pacific Ocean, linking major economies such as European Union, Middle East, India, China, Japan, South Korea, etc. However, the Strait is not deep enough to permit some of the largest ships (mostly oil tankers) to pass through. For example, at Philips Channel, it narrows down to $2.8 \mathrm{~km}$, with $2.1 \mathrm{~km}$ in the shipping lanes, creating one of the world's chokepoints. Since the Strait is vital to the global economy and represents a narrow, shallow, and busy shipping chokepoint, the navigational safety of vessels through the Straits has attracted great attentions from the maritime authorities (e.g. Maritime and Port Authority of Singapore) and other relevant stakeholders (e.g. shippers, carriers, etc.).

Several managerial and navigational solutions have been implemented in the Straits over the past 30 years to enhance navigational safety in the Strait such as the Traffic Separation Scheme (TSS) operated since May $1^{\text {st }}, 1981$. According to TSS, the opposing streams of traffic have been separated by the establishment of traffic lanes. Moreover, in 1998, the International Maritime Organization (IMO) enforced the mandatory Strait ship reporting system (STRAITREP) in the Straits dividing the Straits into 9 Sectors. According to the system, Sectors 7-9 are under the authority of Singapore Vessel Traffic Services (VTS) centre, also called the Singapore Straits, while Sectors 1-5 and Sector 6 fall under the authority of Klang VTS and Johor VTS, respectively. Furthermore, in 1998, the Society of International Gas Tanker and Terminal Operators Ltd (SIGTTO) published the $1^{\text {st }}$ version of Passage Planning Guide: Malacca \& Singapore Straits, including the Straits background and passage notes, to provide guidance of ship masters and navigating officers transiting the Straits (SIGTTO, 2008). The passage notes further segmented the Singapore Strait into 15 legs of the voyage, as showing in Figure 1, where 8 legs are in eastbound and 7 legs in westbound. However, the recommended navigational rules (e.g. speed limit) vary from one leg to another. These rules were set based on the surveys from the ship masters who were experienced and knowledgeable shore-based personnel from various marine organizations by SIGTTO. 


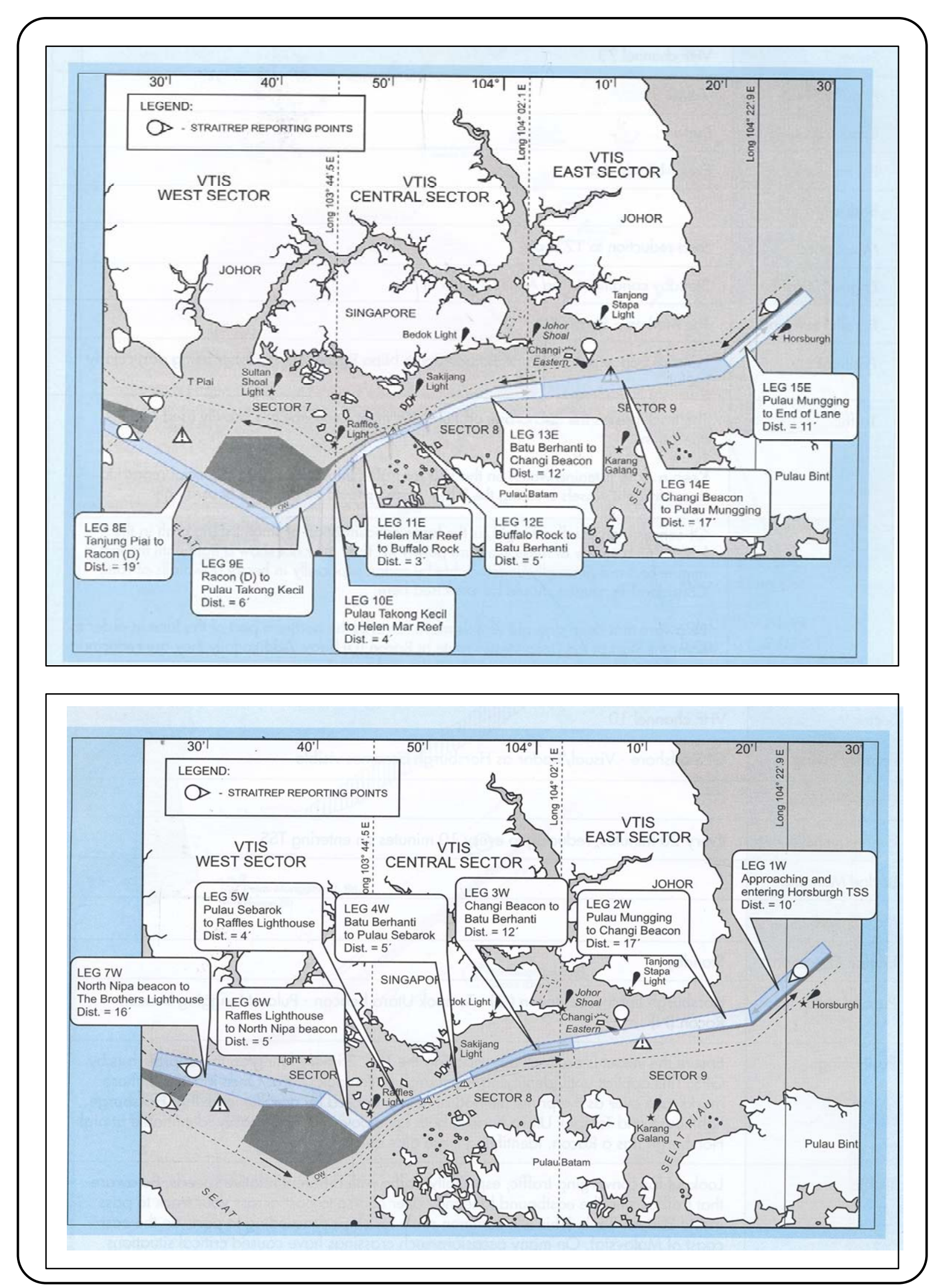

Figure 1: 15 legs in the Singapore Strait

However, the above-mentioned risk reduction solutions are generally based on the qualitative and subjective judgment from experts. There is no existing study to quantitatively 
evaluate ship collision risks in the Straits. It is thus important to propose a procedure to quantitatively evaluate the collision risk in the Singapore Strait to support these expert judgments.

Two speed-related ship collision risk indices from the vehicle collision studies could be adopted as the indices for evaluating the ship collision risks in each leg of the Singapore Strait. Firstly, absolute speed and/or speed dispersion could be applied to evaluate the ship collision risks in shipping channels. In road transportation, various models are developed to reflect the relationship between collision rates and speed (in terms of absolute speed and/or speed dispersion) (Aarts and van Schagen, 2006; Fuller et al., 2009). The collision rates are higher on the roads with a higher speed and/or greater speed dispersion (speed variance). Indeed, greater speed and/or speed dispersion increases the difficulties for drivers to react and response based on common judgment when incidental scenarios take place. According to the Handbook of the Nautical Rules of the Road by Llanna \& Wisneskey, vessels are at risk of collision when they come within a certain distance of their closest point of approach (CPA). Evidently, higher degree of speed dispersion would result in greater variance of headways between consecutive vessels, and thus indicates higher possibility of coming within the CPA. Accordingly, the possibility of collision risks would be higher. Therefore, degree of speed dispersion could be considered as a good macroscopic index to represent the collision risks. Secondly, the degree of acceleration and deceleration can also be considered as a risk index. Vessels may navigate with a constant speed in order to save fuel consumption in open seas. However, in the Singapore Strait, acceleration and deceleration happen under the condition that ships are about to cross, overtake, meet, or turn, namely, scenarios with collision potentials. Higher degree of acceleration and deceleration indicates more frequent occurrence of scenarios with collision potentials. This index is a microscopic way to examine the potential collision risks in the Straits. In addition to speed-related indices, ship domain analysis is also a good tool to estimate the ship collision risk. Fujii and Tanaka (1971) proposed the ship domain concept to estimate the traffic capacity in a shipping waterway. Four years later, Goodwin (1975) defined the ship domain as "the surrounding effective waters which navigator of a ship wants to keep clear of other ships or fixed objects”. Since then, the ship domains have been applied to estimate the frequency of ship collisions (Pietrzykowski, 2008; Pietrzykowski and Uriasz, 2009; Szlapczynski, 2006; Wang, 2010; etc.). Therefore, the ship collision risk for the Strait can also be assessed using the ship domain analysis. 
In order to conduct a quantitative ship collision risk assessment for the Singapore Strait, Lloyd's MIU AIS ship movement database (July 2009) is used in this study. The database with more than four million records provides the unique identification in terms of MMSI (Maritime Mobile Service Identity) number, position (latitude and longitude), spot speed over ground (SOG), and course over ground (COG) at any reporting time (every 1 to 10 minutes) for every ship in the Strait from July $1^{\text {st }}$, to July $31^{\text {st }}$, 2009. It should be pointed out that Lloyd's MIU is reputed on collecting maritime data dating back nearly 300 years ago. They not only purchase Automatic Identification System (AIS) reports from reporting agents (receiving over 12,000 reports per day) but also install receivers in shores nearby the Strait (Gudang terminal, Penang terminal, etc.). The AIS data is an automated tracking system used on ships and by Vessel Traffic Services (VTS) for identifying and locating vessels by electronically exchanging data with other nearby ships and VTS stations (e.g. Singapore VTS). The system may automatically transmit the position and speed of vessels along with the vessel MMSI to an AIS data repository. The International Maritime Organization's International Convention for the Safety of Life At Sea (SOLAS) requires AIS to be fitted aboard international voyaging ships with gross tonnage (GT) of 300 or more tons, and all passenger ships regardless of size.

The objective of this study is to propose a procedure for quantitatively evaluate the collision risks in the Singapore Strait. The navigational rules for various legs recommended by experts could thus be quantitatively verified based on the evaluation results. Three risk indices are applied in this study: index of speed dispersion, degree of acceleration and deceleration, and number of ship domain overlaps. In Section 2, the Lloyd's MIU ship movement database is introduced and these records are pre-processed to eliminate the noises. This is followed by the collision risk assessment for the Strait in Section 3. The results and discussions are illustrated in Section 4 and the last section concludes the study.

\section{Real-time ship movement records pre-processing}

The reporting time and the ship identification provided by Lloyd's MIU AIS ship movement database are highly reliable. However, AIS position and speed data are not immue to errors occurring at the collecting end, at the transmission end, or at the receiving end. For example, the Singapore Strait is a $105 \mathrm{~km}$ long strait between the Strait of Malacca in the west and the South China Sea in the east. The International Hydrographical Organization defines the limits of the Singapore Strait in terms of longitude as $103^{\circ} 21^{\prime} \mathrm{E}$ on the west and $104^{\circ} 35^{\prime} \mathrm{E}$ on the east. However, $0.18 \%$ of records is out of this range and fall in $115^{\circ} \mathrm{E}$ to 
$178^{\circ} \mathrm{E}$ and they are obvious inaccurate records. In addition, the speed limit in most legs of the Strait is 12 knots and it is not possible for vessels sail with a speed in excess of 35 knots. However, $0.25 \%$ of records are with the speeds in excess of 50 knots. We thus need a preprocessing procedure to cleanse the data.

\subsection{Data cleansing}

The noises would significantly influence the ship collision risk assessment for the Singapore Strait. It is not appropriate to delete those records with noises in view of the realtime data integrality. We then propose a data cleansing procedure to eliminate the noises and update those inaccurate records. According to the Newton's laws of motion, the average speed can be calculated as the ratio of journey distance and travelling time. Therefore, the location records and the acceleration/deceleration abilities of vessels can be used to check whether the speed records are within the reasonable range or not. Correspondingly, the location data can be cleansed by using the updated speed data based on the same principle. The data pre-processing is illustrated in detail as follows.

Step 1: check the reasonableness of the speed data.

The time-mean speed for a particular vessel $i$ at a specific time interval $\left[T_{j}, T_{j+1}\right]$ can be estimated by

$$
\bar{V}_{i, T_{j}}=\frac{\sqrt{\left(x_{i, T_{j+1}}-x_{i, T_{j}}\right)^{2}-\left(y_{i, T_{j+1}}-y_{i, T_{j}}\right)^{2}}}{T_{j+1}-T_{j}}
$$

where $x_{i, T_{j}}$ is the longitude coordinate (second) of vessel $i$ at time $T_{j}$ (hour); $y_{i, T_{j}}$ is the latitude coordinate (second) of vessel $i$ in time $T_{j}$ (hour). Note that the coordinators are in terms of second in accordance with the unit of knot (second/hour).

According to the Newton's laws of motion, the time-mean speed should satisfy the conditions as follow:

$$
S O G_{i, T_{j}}-d_{i}\left(T_{j+1}-T_{j}\right) \leq \bar{V}_{i, T_{j}} \leq S O G_{i, T_{j}}+a_{i}\left(T_{j+1}-T_{j}\right)
$$

where $S O G_{i, T_{j}}$ is the speed over ground (knot) of vessel $i$ at time $T_{j}$ (hour); $d_{i}$ and $a_{i}$ are the maximum deceleration and acceleration of vessel $i$, respectively.

Step 2: update the irrational speed data. 
By using the above-mentioned speed verification procedure, $0.34 \%$ speed records are out of the range shown in eqn. (2). The spot SOG related to vessel $i$ at time $T_{j}$ is updated according to the formula:

$$
S O G_{i, T_{j}}^{\prime}=\left\{\begin{array}{l}
\bar{V}_{i, T_{j}}, \text { if the speed is out of range } \\
S O G_{i, T_{j}}, \text { otherwise }
\end{array}\right.
$$

Step 3: check the reasonableness of position data.

Based on the similar procedure, we can compute the positions in terms of latitude and longitude by

$$
\begin{aligned}
& x_{i, T_{j+1}}^{\prime}=x_{i, T_{j}}+S O G_{x}^{\prime} \times\left(T_{j+1}-T_{j}\right) \\
& y_{i, T_{j+1}}^{\prime}=y_{i, T_{j}}+S O G_{y}^{\prime} \times\left(T_{j+1}-T_{j}\right)
\end{aligned}
$$

where $x_{i, T_{j}}^{\prime}$ is the estimated longitude coordinate (second) of vessel $i$ at time $T_{j}$ (hour); $y_{i, T_{j}}^{\prime}$ is the latitude coordinate (second) of vessel $i$ in time $T_{j}$ (hour). The estimated coordinates should satisfy the following equation.

$$
\sqrt{\left(x_{i, T_{j+1}}^{\prime}-x_{i, T_{j+1}}\right)^{2}-\left(y_{i, T_{j+1}}^{\prime}-y_{i, T_{j+1}}\right)^{2}} \leq \frac{1}{2} a_{i}\left(T_{j+1}-T_{j}\right)^{2}
$$

Step 4: update the position data.

Based on the pre-processing procedure above, another $0.1 \%$ of records are updated by using the lower value of estimated coordinates and reporting coordinates (pessimistic risk evaluation).

\section{Ship Collision Risk Assessment for the Singapore Strait}

\subsection{Speed analysis}

Based on the updated ship movement records, the vessel speeds in the Strait are assessed to be relatively low with the exception of only $3.18 \%$ records reflecting speeds in excess of 25 knots. The probable explanation could be that the speed limit in most legs of the Strait is 12 knots. Therefore, absolute speed may not be qualified as a reliable risk index in contrast to speed dispersion. Based on the consultations and discussions with several experienced ship captains, we concluded that it was reasonable that greater differences in speed among vessels are related to a higher collision risk. 
The speed dispersion estimation procedure is as follows. First, we give a ship positioning procedure to group those records into 15 groups (records with respect to 15 legs) based on their position records. In the following, we calculate the time mean speed of vessels transiting through the leg. Third, the speed dispersion can be calculated for each leg.

Ship positioning is to identify in which leg the ship is navigating. In this step, we firstly identify the vertices and edges of each leg. For example, as can be seen in Figure 2, there are five vertices and five edges in Leg $7 \mathrm{~W}$. The longitude and latitude coordinates of all vertices are summarized in Table 1.

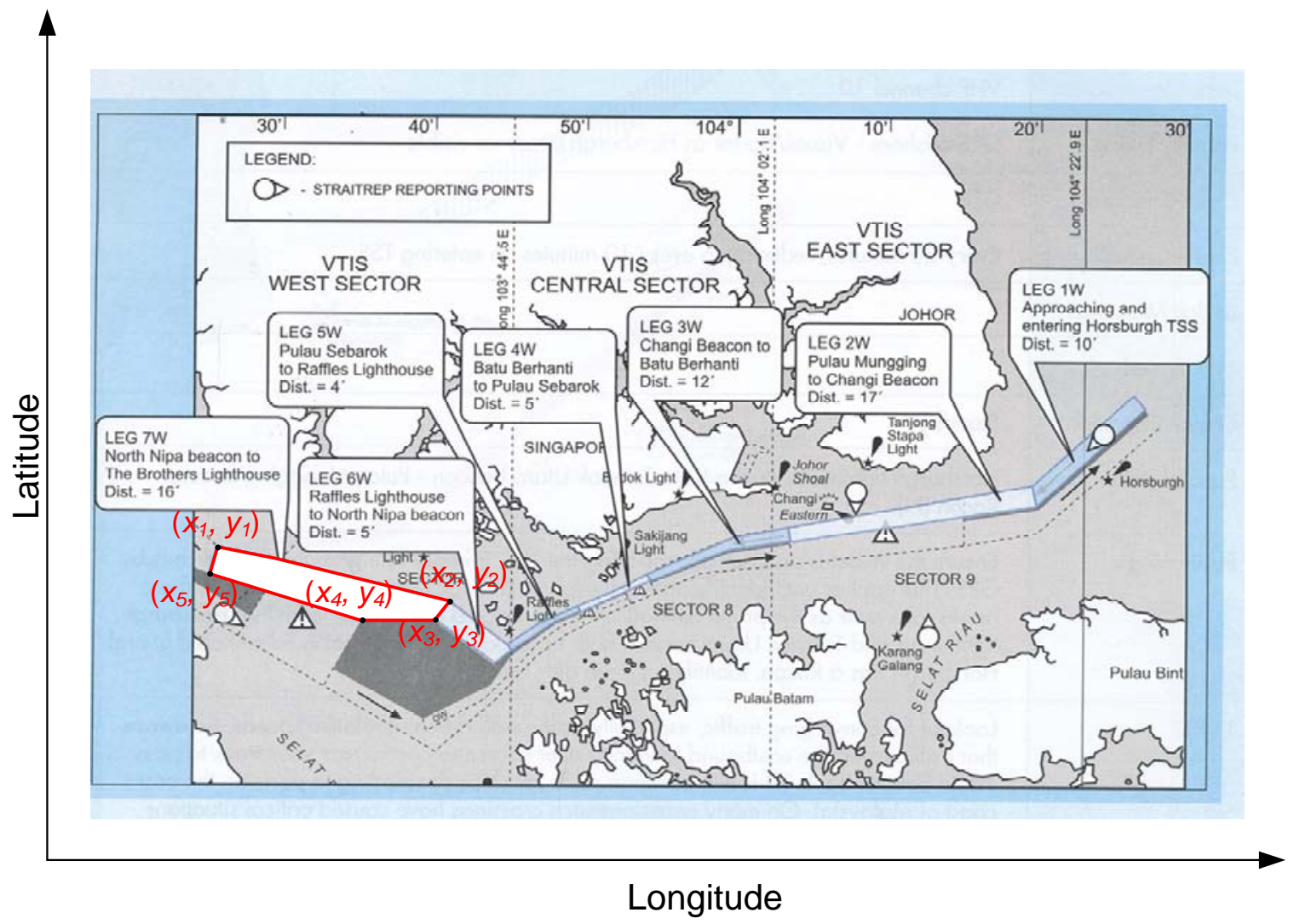

Figure 2: Leg 7W in the Singapore Strait

Table 1: the longitude and latitude coordinates of vertices of Leg 7W

\begin{tabular}{ccc}
\hline Vertices & Longitude $\left(x_{i}\right)$ & Latitude $\left(y_{i}\right)$ \\
\hline$\left(x_{1}, y_{1}\right)$ & $103^{\circ} 26^{\prime} \mathrm{E}$ & $1^{\circ} 16^{\prime} \mathrm{N}$ \\
$\left(x_{2}, y_{2}\right)$ & $103^{\circ} 41^{\prime} \mathrm{E}$ & $1^{\circ} 12^{\prime} \mathrm{N}$ \\
$\left(x_{3}, y_{3}\right)$ & $103^{\circ} 40^{\prime} \mathrm{E}$ & $1^{\circ} 10^{\prime} \mathrm{N}$ \\
$\left(x_{4}, y_{4}\right)$ & $103^{\circ} 36^{\prime} \mathrm{E}$ & $1^{\circ} 10^{\prime} \mathrm{N}$ \\
$\left(x_{5}, y_{5}\right)$ & $103^{\circ} 26^{\prime} \mathrm{E}$ & $1^{\circ} 14^{\prime} \mathrm{N}$ \\
\hline
\end{tabular}


It then proceeds to check (record by record) where the ship at certain time is based on the following approach. Let $x$ and $y$ denote the longitude and latitude coordinates with respect to various records. Then the $x$ and $y$ should satisfy the following equations if the examining record falls in the Leg $7 \mathrm{~W}$.

$$
\begin{aligned}
& y-y_{1} \leq \frac{y_{2}-y_{1}}{x_{2}-x_{1}}\left(x-x_{1}\right) \\
& y-y_{2} \geq \frac{y_{3}-y_{2}}{x_{3}-x_{2}}\left(x-x_{2}\right) \\
& y-y_{3} \geq \frac{y_{4}-y_{3}}{x_{4}-x_{3}}\left(x-x_{3}\right) \\
& y-y_{4} \geq \frac{y_{5}-y_{4}}{x_{5}-x_{4}}\left(x-x_{4}\right) \\
& y-y_{5} \leq \frac{y_{1}-y_{5}}{x_{1}-x_{5}}\left(x-x_{5}\right)
\end{aligned}
$$

By examining the records one by one, we group all the records into 15 categories. For each group (records in the leg), we further group the records in terms of vessel name and calculate the time mean speed for vessel $i\left(\bar{u}_{i}\right)$ by

$$
\bar{u}_{i}=\frac{\sqrt{\left(x_{i}^{T_{i, \max }}-x_{i}^{T_{i, \min }}\right)^{2}+\left(y_{i}^{T_{i, \max }}-y_{i}^{T_{i, \min }}\right)^{2}}}{T_{i, \max }-T_{i, \min }}
$$

where $x_{i}^{T}$ and $y_{i}^{T}$ are the longitude and latitude coordinates of vessel $i$ at time $T ; T_{i \text {,max }}$ and $T_{i \text {,min }}$ are the maximum (latest) and minimum (earliest) time that vessel $i$ in this leg (group). It should be pointed out that all the motionless vessels (vessels with speed lower than 0.1 knots) are not at the traffic waterways but at the fairways (port areas). Therefore, those motionless vessels do not affect the collision risk in the shipping lanes. After obtaining the time mean speed for all the ships of various legs, the speed dispersion in various shipping legs can be calculated accordingly.

This index is a macroscopic risk index for collision risk in various legs. All the updated ship movement records are incorporated to represent the relative measure of collision risk. Based on the expert judgment from ship captains, greater speed variance indicates higher likelihood of vessel collision. 


\subsection{Deceleration \& acceleration analysis}

Vessels navigate with a constant speed in order to save fuel consumption in open seas. Acceleration and deceleration happen under the condition that ships are about to cross, overtake, meet, or turn, namely, scenarios with collision potentials. Accordingly, the degree of acceleration and deceleration can be considered as a collision risk index.

In order to calculate the degree, we will also firstly group the records based on the location and vessels' MMSI numbers. In Step 2, we calculate the acceleration and deceleration for consecutive records vessel by vessel by

$$
a_{k, i, T_{j}}=\frac{S O G_{k, i, T_{j}}-S O G_{k, i, T_{j-1}}}{T_{j}-T_{j-1}}
$$

where $a_{k, i, T_{j}}$ is the acceleration or deceleration of vessel $i$ in Leg $k$ at time $T_{j-1} ; S O G_{k, i, T}$ is the speed over ground of vessel $i$ in Leg $k$ at time $T$. In this study, we take the average of the square values of acceleration and/or deceleration as another collision risk index by

$$
\bar{A}_{k}=\frac{\sum_{i=1}^{I_{k}} \sum_{j=1}^{J_{i, k}} a_{k, i, T_{j}}^{2}}{I_{k}}
$$

where $\bar{A}_{k}$ is the degree of acceleration and deceleration; $J_{i, k}$ is the number of records of vessel $i$ in Leg $k$.

This index can be considered as a microscopic way to examine the potential ship collision risk in the Straits. It should be pointed out that, in some circumstances, small speed variance and/or gentle acceleration and deceleration may also be correlated with high ship collision potentials. This because not only the speed over ground (SOG) but also course over ground (COG) has an substantial impact on collision risk (Macduff, 1974; Kaneko, 2002; etc.). For example, ferries through passing the Strait, which navigate perpendicular to the shipping lanes at a very high speed (around 25 knots in average), may have a significant interference with the vessels in the shipping lanes. The impact of these vessels should be taken into consideration in the risk assessment. Accordingly, we applied the concept of ship domain to take not only SOG but also COG into account.

\subsection{Ship domain analysis}

\subsubsection{Ship domain and collision risk}

The concept of ship domain plays an essential role in navigational safety of vessels. A well known definition of ship domain by Goodwin (1975) is described as "the surrounding 
effective waters which the navigators of a ship want to keep clear of other ships or fixed objects”. Various geometrical ship domains with distinct shapes and sizes were proposed by researchers (Fujii and Tanaka, 1971; Goodwin, 1975; Davis et al., 1982; etc.). Figure 3 illustrates the Fujii ship domain and Goodwin ship domain.

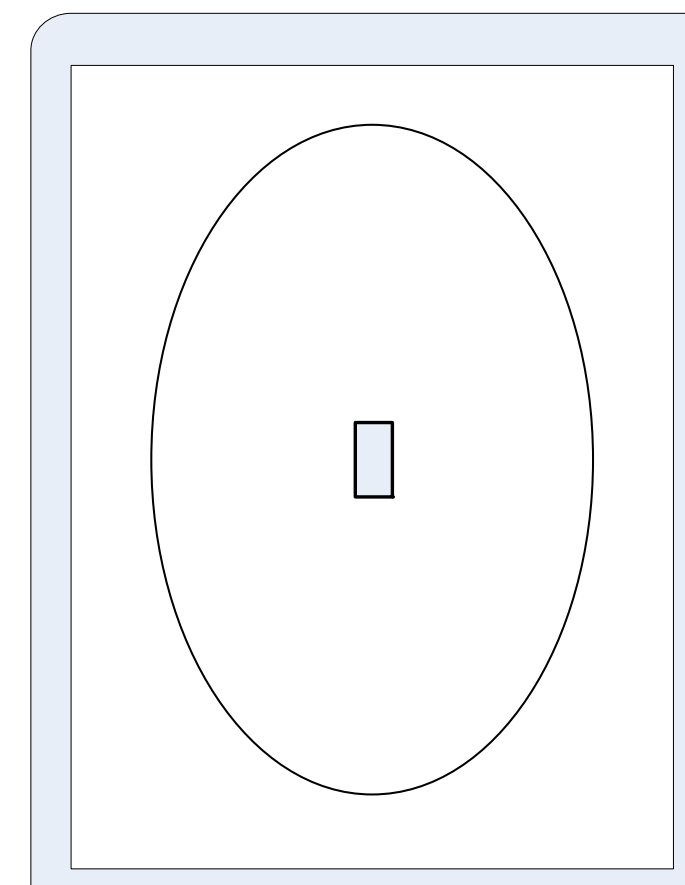

(a) Fujii domain

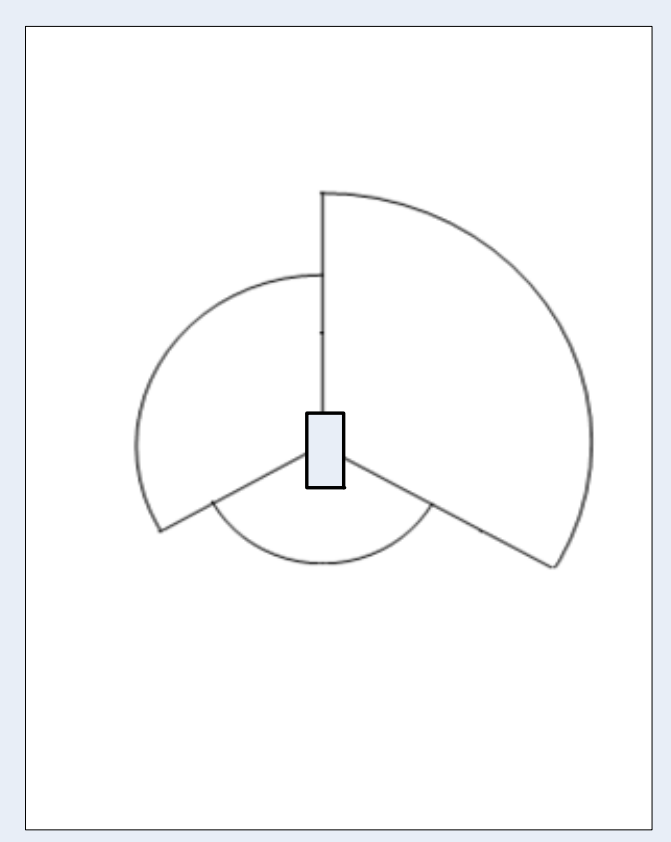

(a) Goodwin domain

Figure 3: Fujii domain and Goodwin domain

Ship domain is particularly useful in restricted waters such as Strait (Pietrzykowski, 2008). The classical definition of ship domain categorized the waters around a vessel into two zones: dangerous (inside ship domain) and safe (outside ship domain). As mentioned in Zhao et al. (1993), Pietrzykowski (2008), and Wang (2010), human beings tend to distinguish the area around ships to be more descriptive than binary judgment. The waters may be described as very safe, safe, less safe, dangerous, and very dangerous depending on the distance to the vessels, which is called fuzzy ship domain, which has been employed to evaluate the collision risks in restricted waters (Pietrzykowski, 2008; Wang, 2010). As ship domain refers to waters that navigators want to keep clear of other ships, the overlaps of ship domains indicates higher likelihood of ship collisions. Evidently, the more ship domain overlapping scenarios happen in one certain leg, the riskier the leg is.

\subsubsection{Fuzzy quaternion ship domain}


A unified fuzzy quaternion ship domain (FQSD) is proposed by Wang (2010), formulated by

$$
F_{Q S D}(r)=\left\{(x, y) \mid f_{k}(x, y ; Q(r) \leq 1, k \geq 1)\right\}
$$

where

$$
\begin{array}{r}
f_{k}(x, y ; Q(r))=\left(\frac{2 x}{(1+\operatorname{sgn} x) R_{\text {fore }}(r)+(1-\operatorname{sgn} x) R_{\text {aft }}(r)}\right)^{k} \\
+\left(\frac{2 y}{(1+\operatorname{sgn} y) R_{\text {starb }}(r)+(1-\operatorname{sgn} y) R_{\text {port }}(r)}\right)^{k} \\
Q(r)=\left\{R_{\text {fore }}(r), R_{\text {aft }}(r), R_{\text {starb }}(r), R_{\text {port }}(r)\right\}, 0<r<1 \\
R_{i}(r)=\left(\frac{\ln \frac{1}{r}}{\ln 2}\right)^{\frac{1}{k}} R_{i}, i \in\{\text { fore, aft starb, port }\}, 0<r<1
\end{array}
$$

where possibility value $r \in(0,1)$ is used to determine the fuzzy boundary (the values of radii) of the FQSD; $R_{\text {fore }}(r), R_{\text {aft }}(r), R_{\text {starb }}(r)$, and $R_{\text {port }}(r)$ represent the forward radius, backward radius, starboard side radius, and port side radius, respectively; $\mathrm{k}$ is the shape index of the FQSD. From the definition, the higher the $r$ value is, the smaller the corresponding fuzzy ship domain is.

\subsubsection{Fuzzy ship domain based vessel collision risk assessment}

The number of ship domain overlaps is used to represent the collision risk based on ship domain. Not only SOG but also COG is taken into consideration in ship domain analysis. The procedure of estimating ship domain overlapping scenarios is summarized as follows.

Firstly, we should estimate the locations and speeds of all the vessels at the examining time $T_{j}$. Since those vessels may take 30 to 60 minutes to pass through a certain leg, we thus determine that the systems will be examined twice per hour (48 times per day). We shall apply the recent improvements to process the AIS data for location and speed estimation purposes (van Dorp and Merrick, 2009). Let $\left\{\left(x_{1}, y_{1}, v_{1}, c_{1}, t_{1}\right), \cdots,\left(x_{n}, y_{n}, v_{n}, c_{n}, t_{n}\right)\right\}$ denote a series of longitude and latitude coordinates, speed over ground, course over ground, and reporting time which defines a recorded route of a vessel transiting in the Singapore Strait. Each transit may include up to 300 points. For one particular time $T_{j}$, we propose the 
weighted mean summation to estimate the position of the vessel at time $T_{j}$ based on Newton's laws of motion as follows.

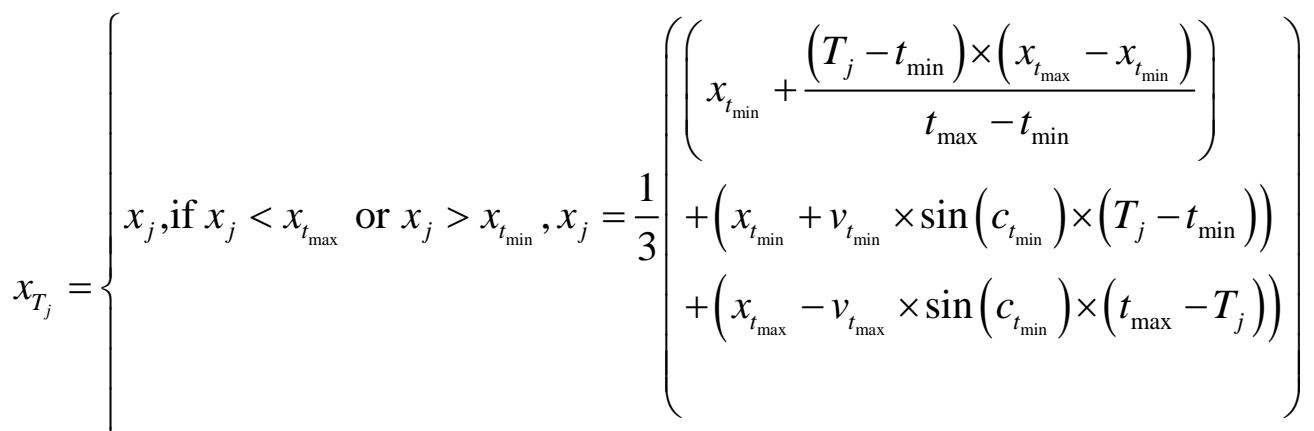

$$
\begin{aligned}
& x_{t_{\min }}+\frac{\left(T_{j}-t_{\min }\right) \times\left(x_{t_{\max }}-x_{t_{\min }}\right)}{t_{\max }-t_{\min }}, \text { otherwise }
\end{aligned}
$$

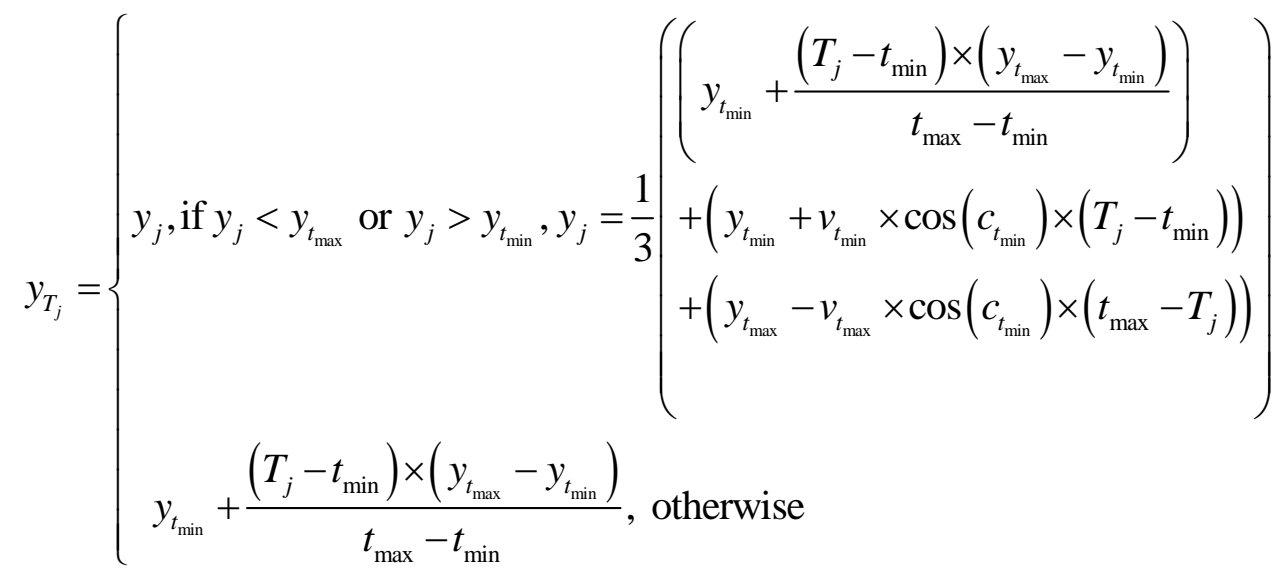

Secondly, we draw the ship domain at examining time $T_{j}$ with different possibility value $r$ for all the vessels based on the definition of FQSD. Note that the estimated position data are used to determined the ship domain boundary of various vessels at the examining time $T_{j}$. Thirdly, the number of ship domain overlaps could be counted at all the examining time and the positions of overlaps could also be recorded. Lastly, the recorded positions of overlaps are grouped by using ship positioning approach illustrated in Section 3.1.

\section{Results and discussions}

\subsection{Results}

Based on the methodology proposed in Section 3, we could calculate the index of speed dispersion, degree of acceleration and deceleration, and number of FQSD overlaps. Note that the first order shape index of FQSD $(k=1)$ is applied in this study. The radii of FQSD are estimated below based on the model proposed by Kijima (2003). 


$$
\left\{\begin{array}{l}
R_{\text {fore }}=\left(1+1.34 \sqrt{1.55 v^{0.72}+0.17 v^{1.09}}\right) L \\
R_{a f t}=\left(1+0.67 \sqrt{1.55 v^{0.72}+0.17 v^{1.09}}\right) L \\
R_{\text {starb }}=\left(0.2+0.83 v^{0.5441}\right) L \\
R_{\text {port }}=\left(0.2+0.62 v^{0.5441}\right) L
\end{array}\right.
$$

The summary of ship collision risk assessment is tabulated in Table 2. Note that number of ship domain with possibility value $r=0.8$ overlaps is 0 for all legs and we thus do not list in the table.

Table 2: Risk assessment results based on records (July $1^{\text {st }}, 2009$ to July $31^{\text {st }}$, 2009)

\begin{tabular}{cccccc}
\hline & $\begin{array}{c}\text { Index of } \\
\text { speed }\end{array}$ & $\begin{array}{c}\text { Degree of } \\
\text { acceleration and } \\
\text { dispersion }\end{array}$ & \multicolumn{3}{c}{ Number of ship domain overlaps } \\
\cline { 5 - 6 } & deceleration & $r=0.6$ & $r=0.4$ & $r=0.2$ \\
\hline Leg 1W & 4.78 & 0.65 & 0 & 39 & 42 \\
Leg 2W & 4.5 & 0.69 & 0 & 168 & 199 \\
Leg 3W & 4.19 & 0.9 & 6 & 307 & 381 \\
Leg 4W & 5.43 & 0.98 & 21 & 391 & 489 \\
Leg 5W & 5.42 & 1.01 & 12 & 327 & 351 \\
Leg 6W & 3.83 & 1.21 & 2 & 214 & 254 \\
Leg 7W & 4.69 & 0.91 & 6 & 186 & 287 \\
Leg 8E & 4.65 & 0.92 & 0 & 112 & 176 \\
Leg 9E & 3.91 & 0.32 & 3 & 263 & 177 \\
Leg 10E & 4.33 & 1.08 & 12 & 319 & 371 \\
Leg 11E & 6.12 & 1.07 & 14 & 359 & 394 \\
Leg 12E & 5.23 & 1.14 & 17 & 329 & 367 \\
Leg 13E & 4.79 & 0.81 & 7 & 309 & 328 \\
Leg 14E & 5.13 & 0.91 & 0 & 151 & 207 \\
Leg 15E & 2.91 & 0.62 & 0 & 4 & 9 \\
\hline
\end{tabular}

\subsection{Discussions}

Legs $4 \mathrm{~W}$ and 12E have long been well recognized as the geographical chokepoints of the Straits of Malacca and Singapore. This is because the two legs represent the narrowest point with only 1.2 miles wide shipping lane with $<21$ meters draft, located near Batu Berhanti. Based on our results, the indices of speed dispersion for Legs $4 \mathrm{~W}$ and 12E are 5.43 and 5.23, respectively; the degrees of acceleration and deceleration for the two legs are 0.98 and 1.14 , respectively. Therefore, we choose "index of speed dispersion $>5$ ", "degree of acceleration > 0.9 ", and "number of ship domain $(r=0.4)$ overlaps $>300$ " as risk criteria. We can also use other risk criteria to identify the risky legs since the relative safety levels of various legs are obtainable based on the three risk indices. The risky legs are represented in Figure 4. 


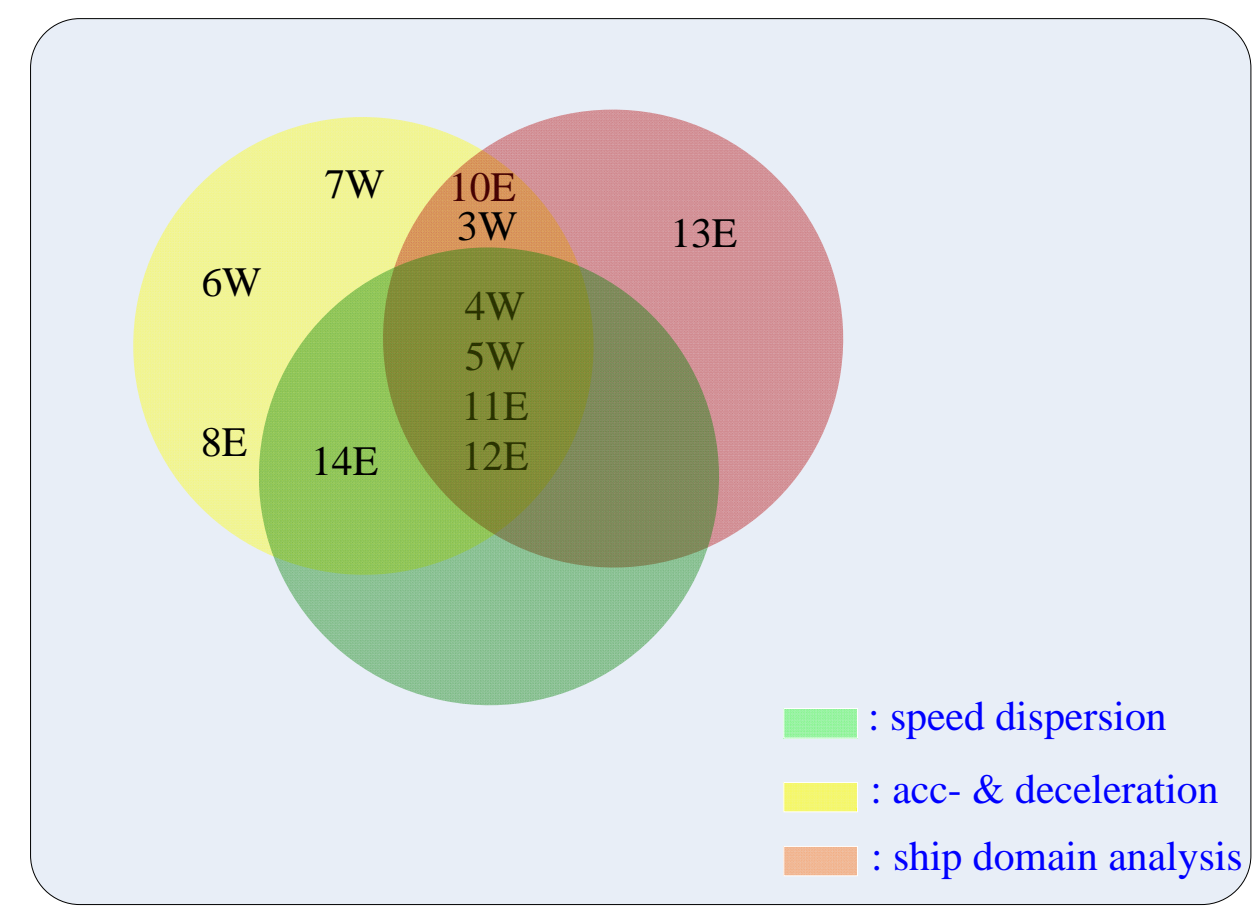

Figure 4: Illustrative results of risk assessment

According to Passage Planning Guide: Malacca \& Singapore Straits, the vessels commence reducing speed to 12 knots in Legs 8E and 3W. Vessels in Legs 13E and 7W are about to increase speed from 12 knots if conditions are suitable. Presumably, the degree of deceleration and acceleration should be greater in the above-mentioned four legs than those with respect to other legs. Based on the data analysis, we find that Legs $3 \mathrm{~W}, 7 \mathrm{~W}$, and $8 \mathrm{E}$ are characterized with higher degree of deceleration and accelerations $(>0.9)$ as oppose to the vessels in 13E. The probable explanation could be that majority of vessels increase speed in Leg 14E rather than 13E.

The speed limit in Legs 4W, 5W, 6W, 9E, 10E, 11E, and 12E is 12 knots. However, data analysis shows that quit a number of vessels navigate with a greater speed. The data are summarized in Table 3.

Table 3: Speed limit analysis

\begin{tabular}{ccccc}
\hline Leg & Speed limit & $\begin{array}{c}\text { Speeding } \\
\text { vessels }\end{array}$ & $\begin{array}{c}\text { Speeding cargo } \\
\text { vessels }\end{array}$ & $\begin{array}{c}\text { 85\% percentile speed } \\
\text { (cargo ship) }\end{array}$ \\
\hline 4W & 12 knots & $23.79 \%$ & $22.36 \%$ & 19.1 knots \\
5W & 12 knots & $27.55 \%$ & $25.62 \%$ & 18.7 knots \\
6W & 12 knots & $35.35 \%$ & $31.11 \%$ & 21.5 knots \\
\hline
\end{tabular}




\begin{tabular}{ccccl}
\hline $9 \mathrm{E}$ & 12 knots & $27.97 \%$ & $26.85 \%$ & 17.8 knots \\
$10 \mathrm{E}$ & 12 knots & $13.58 \%$ & $12.77 \%$ & 18.9 knots \\
$11 \mathrm{E}$ & 12 knots & $27.22 \%$ & $25.59 \%$ & 19.4 knots \\
$12 \mathrm{E}$ & 12 knots & $31.48 \%$ & $28.96 \%$ & 17.5 knots \\
\hline
\end{tabular}

As can be seen in Figure 1, Leg 6W is comparatively wider than other legs. This may be the reason why the speeding vessels in the leg are more than those in other legs. It should be pointed out that more vessels in Leg 12E are categorized into “other ships” (e.g. passenger ships). Majority of passenger ships sails with a much higher speed than cargo ships. For example, the passenger ship with MMSI number 563011120 sails with a speed of 27.3 knots in Leg $12 \mathrm{E}$ on July $18^{\text {th }}$, 2009. This is the reason why Leg $12 \mathrm{E}$ has more speeding vessels.

In order to evaluate the impact of speeding of vessels, an impact analysis is conducted by using speed dispersion analysis. We assume that all the speeding cargo vessels sail at a speed of 12 knots to conduct the speed dispersion analysis again and the results are tabulated in Table 4.

Table 4: Speed dispersion analysis

\begin{tabular}{cccc}
\hline & Speed limit & Speed dispersion & $\begin{array}{c}\text { Speed dispersion } \\
\text { (if no speeding vessels ) }\end{array}$ \\
\hline Leg 4W & 12 knots & 5.43 & 2.95 \\
Leg 5W & 12 knots & 5.42 & 2.68 \\
Leg 6W & 12 knots & 3.83 & 2.91 \\
Leg 9E & 12 knots & 3.91 & 3.01 \\
Leg 10E & 12 knots & 4.33 & 2.75 \\
Leg 11E & 12 knots & 6.12 & 2.70 \\
Leg 12E & 12 knots & 5.23 & 2.89 \\
\hline
\end{tabular}

From Table 4, we can see that the index of speed dispersion is much smaller if all vessels sail within the speed limit. The speeding vessels are therefore considered as great threats to the safety level of the Strait.

\section{Conclusions and Recommendations}

In this study, we proposed three ship collision risk indices: index of speed dispersion, degree of acceleration and deceleration, and number of ship domain overlaps. The Lloyd's 
MIU AIS ship movement database is applied in this study after a data-cleansing procedure. Based on the three risk indices, Legs $4 \mathrm{~W}, 5 \mathrm{~W}, 11 \mathrm{E}$, and 12E are considered as the most risky legs in the Strait. The risk reduction solutions should be prioritized being implemented in the above-mentioned four legs. It should be pointed out that quite a number of cargo vessels (around 25\%) sail with a speed beyond speed limit, which results in higher potentials of vessel collision. Impact analysis indicates that the safety level would be significantly enhanced if all the vessels follow the passage guidelines. The speed limit and passage notes are just a recommended rule for vessels passing through the Strait at present. However, according to the review of maritime transport 2008 published by the United Nations Conference on Trade and Development, global maritime trade is predicted to increase by 44\% in 2020 and doubled by 2031 (UNCTAD, 2008). This would result in an increase of the maritime traffic volume through the Singapore Strait accordingly. By then, the necessary risk reduction solutions such as compulsory speed limit should be implemented to assure the safe navigation in the Singapore Strait.

\section{Acknowledgments}

This paper is supported by the research project "Development of QRA model and software for shipping operations in the Straits of Malacca and Singapore” funded by Maritime Innovation and Technology Fund (WBS No. R-264-000-281-490 and R-702-000-004-490).

\section{References}

Aarts, L., I., van Schagen, 2006. Driving speed and the risk of road crashes: A review. Accident Analysis and Prevention 38, 215-224.

Fujii, Y., Tanaka, K., 1971. Traffic capacity. Journal of Navigation 24(4), 543-552.

Fuller, R., Gormley, M., Stradling, S., Broughton, P., Kinnear, N., C’Dolan, C., and B., Hannigan, 2009. Impact of speed change on estimated journey time: Failure of drivers to appreciate relevance of initial speed. Accident Analysis and Prevention 41(1), 1014.

Gilmartin, H., 2008. EU - U.S. -China: Cooperation in the Malacca Straits. Hamburg, Nov. 2008.

Goodwin, E.M., 1975. A statistical study of ship domains. Journal of Navigation 28(3), 328344.

Kaneko, F., 2002. Methods for probabilistic safety assessments of ships. Journal of Marine Science and Technology 7(1), 1-16. 
Kijima, K., Furukawa, Y., 2003. Automatic collision avoidance system using the concept of blocking area. Proceeding of IFAC Conference on Manoeuvring and Control of Marine Craft, Girona, Spain

Macduff, T., 1974. Probability of vessel collisions. Ocean Industry 9(9),144-148.

Pietrzykowski, Z., 2008. Ship’s fuzzy domain - a criterion for navigational safety in narrow fairways. Journal of Navigation 61(3), 499-514.

Pietrzykowski, Z., Uriasz, J., 2009. The ship domain - a criterion of navigational safety assessment in an open sea area. Journal of Navigation 62(1), 93-108.

SIGTTO, 2008. Passage Planning Guide: Malacca \& Singapore Straits (2nd Edition 2008). Witherby Seamanship International Ltd.

Szlapczynski, R., 2006. A unified measure of collision risk derived from the concept of a ship domain. Journal of Navigation 59(3), 477-490.

UNCTAD. Review of $\quad$ Maritime $\quad$ Transport 2008. http://www.unctad.org/Templates/WebFlyer.asp?intItemID=4659\&lang=1 Accessed on February 8 ${ }^{\text {th }}, 2011$.

Van Dorp, J.R., Merrick, J.R.W., Harrald, J.R., Mazzuchi, T.A, Grabowski, M., 2001. A risk management procedure for the Washington state ferries. Risk Analysis 21(1), 127142.

Wang, N., 2010. An intelligent spatial collision risk based on the quaternion ship domain. Journal of Navigation 63(4), 733-749.

Zhao, J., Wu, Z., Wang, F., 1993. Comments on ship domains. Journal of Navigation 46(3), 422-436. 